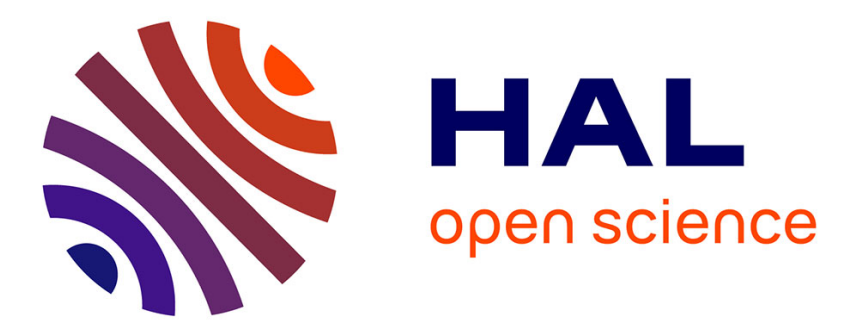

\title{
APOL1 polymorphisms and development of CKD in an identical twin donor and recipient pair.
}

Tomek Kofman, Vincent Audard, Céline Narjoz, Olivier Gribouval, Marie

Matignon, Claire Leibler, Dominique Desvaux, Philippe Lang, Philippe

Grimbert

\section{To cite this version:}

Tomek Kofman, Vincent Audard, Céline Narjoz, Olivier Gribouval, Marie Matignon, et al.. APOL1 polymorphisms and development of CKD in an identical twin donor and recipient pair.: Kidney donation in twins with APOL1 variant. American Journal of Kidney Diseases, 2014, 63 (5), pp.816-9. 10.1053/j.ajkd.2013.12.014 . inserm-01002129

\section{HAL Id: inserm-01002129 https://www.hal.inserm.fr/inserm-01002129}

Submitted on 5 Jun 2014

HAL is a multi-disciplinary open access archive for the deposit and dissemination of scientific research documents, whether they are published or not. The documents may come from teaching and research institutions in France or abroad, or from public or private research centers.
L'archive ouverte pluridisciplinaire HAL, est destinée au dépôt et à la diffusion de documents scientifiques de niveau recherche, publiés ou non, émanant des établissements d'enseignement et de recherche français ou étrangers, des laboratoires publics ou privés. 


\section{APOL1 Polymorphisms and Development of Chronic Kidney Disease in an Identical Twin Donor and Recipient Pair}

Tomek Kofman , $\mathrm{MD}^{1}$, Vincent Audard, $\mathrm{MD}, \mathrm{PhD}^{1}$, Céline Narjoz, $\mathrm{MD}^{2}$, Olivier Gribouval, $\mathrm{PhD}^{3,4}$, Marie Matignon, $\mathrm{MD}^{1}$, Claire Leibler, $\mathrm{MD}^{1}$, Dominique Desvaux, $\mathrm{MD}^{1}$, Philippe Lang, $\mathrm{MD}, \mathrm{PhD}^{1}$, Philippe Grimbert, $\mathrm{MD}, \mathrm{PhD}^{1}$.

1. Service de Néphrologie et Transplantation, Hôpital Henri Mondor, Centre de référence maladie rare Syndrome Néphrotique Idiopathique, Institut Francilien de recherche en Néphrologie et Transplantation (IFRNT), INSERM U955, Université Paris Est Créteil, APHP (Assistance Publique-Hôpitaux de Paris, Créteil), Créteil, France

2. Université Paris Descartes, INSERM UMR-S 775, 45 rue des Saints-Pères, Paris, France. Assistance Publique Hôpitaux de Paris, Hôpital Européen Georges Pompidou, Service de Biochimie, Unité Fonctionnelle de Pharmacogénétique et Oncologie Moléculaire, Paris, France.

3. Inserm U983, Hôpital Necker-Enfants Malades, Paris, France

4. Université Paris Descartes, Sorbonne Paris Cité, Institut Imagine, Paris, France

*Corresponding author: Tomek Kofman, Nephrology and Transplantation Department, Henri Mondor Hospital, AP-HP, Institut Francilien de recherche en Néphrologie et Transplantation (IFRNT) Paris Est Créteil University, Créteil, France. Telephone number: +33149812460, Fax number: +33149812452, Email: thomas.kofman@hmn.aphp.fr

Abstracts words count: 162

Manuscript word counts: 1379

Short title: Kidney donation in twins with APOL1 variant

Disclosure

The authors of this manuscript have no conflict of interest to disclose as described by the American Journal of Kidney disease. 


\begin{abstract}
We report the occurrence of chronic kidney disease after living-related kidney transplant involving monozygotic twin brothers of Afro-Caribbean origin who were both heterozygous for the G1 and G2 APOL1 kidney disease risk alleles. A 21 year-old black man with endstage kidney disease of unknown aetiology received a kidney from his monozygotic twin brother (confirmed by microsatellite analysis). Thirty months after transplantation, the patient presented proteinuria and decreased eGFR with typical focal segmental glomerulosclerosis lesions on the graft biopsy. He received steroid therapy, but progressed to kidney failure 5 years later. The twin brother displayed normal kidney function without proteinuria at the time of transplant; however, 7 years later, he exhibited decreased estimated GFR (40 $\mathrm{ml} / \mathrm{min} / 1.73 \mathrm{~m})$ and proteinuria $(2.5 \mathrm{~g} /$ day $)$. APOL1 genotyping of revealed that both donor and recipient were heterozygous for the G1 and G2 alleles. This unique case is in stark contrast to expectations for identical twin transplantation and suggests a role for APOL1 polymorphisms in both the donor and recipient.
\end{abstract}

Key words: APOL1 polymorphism, donor, kidney transplantation, outcome 


\section{Introduction}

The risk of non-diabetic chronic kidney disease (CKD) is 4-5 times higher for people of African ancestry than other groups ${ }^{1,2}$. This was recently attributed to two sequence variants, G1 and G2, in the last exon of the APOL1 gene, encoding apolipoprotein L-1: these variants are common in African Americans but absent from people of European ancestry ${ }^{3}$. People with two risk alleles have an increased risk of focal and segmental glomerulosclerosis (FSGS), hypertension-related end-stage renal disease (ESRD), and HIV-associated nephropathy ${ }^{3-5}$. The ethnic origin of kidney transplantation recipients may influence the graft function outcome, and recipients with African ancestry are usually considered as at high risk of poor kidney outcome, although a French survey does not support this view $^{6-9}$. The relationship between APOL1 risk variant alleles and allograft survival after kidney transplantation has been evaluated in two recent studies ${ }^{10,11}$. The first study, with 2 years of post-transplant follow-up, showed that graft survival was significantly shorter in transplant recipients of donor kidneys with two APOL1 risk variant alleles ${ }^{11}$. By contrast, a retrospective study did not find that the 5-year post-transplant graft survival correlated with the APOL1 genotype of the recipient ${ }^{10}$. Further investigations are required to clarify the consequences of both recipient and donor APOL1 genotype on the graft outcome after kidney transplantation. We describe here, for the first time, FSGS of the graft after a living-related kidney transplant and unsatisfactory kidney function outcome in the donor for a pair of monozygous twin brothers sharing the same APOL1 risk variant genotype. 


\section{Case report}

A 21-year-old man of Caribbean origin was referred to our Nephrology department in 2006 for a first kidney transplantation. His medical history included ESRD of unknown origin requiring intermittent haemodialysis diagnosed one year before. No kidney biopsy was performed at the time of the first nephrological evaluation because kidney function was significantly abnormal (creatinine at $8.54 \mathrm{mg} / \mathrm{dL}$, estimated glomerular filtration rate, (eGFR) was $10 \mathrm{ml} / \mathrm{min} / 1.73 \mathrm{~m}^{2}$ according to the 6 -variable MDRD formula ${ }^{12}$ ) in a context of bilateral kidney atrophy. Nevertheless, initial clinical findings revealed high blood pressure (170/85 $\mathrm{mmHg})$ with significant proteinuria $(3.4 \mathrm{~g} /$ day $)$. There was no leucocyturia nor hematuria. The historical, immunological and viral screening including drug abuse, HIV serology, anti nuclear factor was negative. He underwent kidney transplantation with the left kidney from his identical twin brother. Twinship was confirmed by microsatellite analysis. At the time of kidney transplantation, the creatinine level for the donor twin was $1.18 \mathrm{mg} / \mathrm{dL}$ (eGFR: 100 $\mathrm{ml} / \mathrm{min} / 1.73 \mathrm{~m}^{2}$ ) without significant proteinuria (0.005 g/day). The donor had normal blood pressure. The pretransplant panel reactive antibody level was $0 \%$. Immunosuppresive treatment consisted of steroid therapy exclusively: one pulse of methylprednisolone on two consecutive days then oral prednisone at $1 \mathrm{mg} / \mathrm{kg} / \mathrm{day}$ progressively tapered and definitively stopped 15 days after surgical procedure. The post-transplantation course was unremarkable and kidney function on day 10 post-transplantation was optimal (creatinine $1.18 \mathrm{mg} / \mathrm{dL}$, eGFR: $100 \mathrm{ml} / \mathrm{min} / 1.73 \mathrm{~m}^{2}$ ). Six months after transplantation, the patient presented with an increase of proteinuria (1.2 g/day) associated with severe hypertension requiring antihypertensive therapy (amlodipine, irbesartan and hydrochlorothiazide). Kidney function remained unchanged and a biopsy was performed but was not informative. Thirty months after transplantation, he presented with significant decreased eGFR (creatinine $2.56 \mathrm{mg} / \mathrm{dL}$, eGFR $43 \mathrm{ml} / \mathrm{min} / 1.73 \mathrm{~m}^{2}$ ) and persistent proteinuria (2.2 g/day). A second kidney biopsy 
showed lesions typical of FSGS on three of 15 glomeruli analyzed (Figure 1A and 1B). The biopsy showed moderate interstitial fibrosis and tubular atrophy. Vessels appeared normal. Immunofluorescence study demonstrated segmental deposits of IgM and C3 in the areas of scarring. C4d immunostaining was negative. Our patient was treated with $1 \mathrm{mg} / \mathrm{kg}$ prednisone for 4 months for late recurrence of primary FSGS nephropathy on the graft. Unfortunately, kidney function declined progressively (Creatinine $12.27 \mathrm{mg} / \mathrm{dL}$, eGFR $6 \mathrm{ml} / \mathrm{min} / 1.73 \mathrm{~m}^{2}$ ) with increase of proteinuria. No other treatment such as plasmapheresis or Rituximab was performed. Five years after transplantation, a third biopsy demonstrated extensive interstitial fibrosis (65\% of total parenchyma) with severe glomerular involvement ( $70 \%$ of glomeruli obsolescent). The patient was prepared for chronic haemodialysis.

Seven years after donation, the donor displayed significant proteinuria ( $2.53 \mathrm{~g} /$ day $)$ without haematuria but associated with decreased eGFR (creatinine $2.5 \mathrm{mg} / \mathrm{dL}$; and eGFR: 40 $\mathrm{ml} / \mathrm{min} / 1.73 \mathrm{~m}^{2}$ ) (Figure 2). We did not perform a kidney biopsy on the remaining kidney.

The synchronous apparition of kidney disease may point toward a hereditary FSGS. As Lipska et al recently suggested ${ }^{13}$, we performed the sequencing of the integrality of podocin gene and did not identify any mutation. In the light of recent reports of genetic susceptibility associated with FSGS in people of African ancestry, we genotyped the APOL1 gene in both donor and recipient and both were heterozygous for the G1 and G2 APOL1 risk alleles (Figure 3).

\section{Discussion}

We report here the first case of a decreased eGFR in both donor and recipient after living-related kidney transplantation involving twin brothers with APOL1 polymorphisms.

This critical issue contrasts with the excellent expected outcome in a living donation between two monozygotic twins. A recent study clearly indicates that kidney allograft survival is 
shorter in patients receiving deceased donor kidneys from African Americans with two APOL1 risk alleles than those receiving other kidneys ${ }^{11}$. Based on these findings, it was suggested that APOL1 status should be used for potential live kidney donors. However, this association had not been established in 2006, so no such screening was performed in the present case at the time of transplant. Our recipient exhibited an early FSGS recurrence leading to ESRD only five years after transplantation. This outcome is in agreement with the Kaplan-Meier kidney allograft survival observed in the study from Reeves-Daniel: only 50\% of grafts survived at 5 years in the cohort of patients carrying the same haplotype ${ }^{11}$.

Another major issue is the risk of the donor developing accelerated kidney disease after donation. Can kidney disease related to APOL1 polymorphisms be triggered or accelerated by kidney donation? Surprisingly, there is currently no data available relative to clinical outcome in living relative donors carrying APOL1 polymorphisms. Based on the logic that close relatives of African-American ESRD patients with APOL1-related kidney failure are likely to share one or more APOL1 risk alleles, Cohen et al proposed a screening programme for self-identified, potential, African-American live donors ${ }^{14}$. In our case, the donor exhibited a marked decline in kidney function and significant proteinuria 5 years after donation without risk factor for developing post-donation kidney failure at the time of transplantation except donor origin. Linkage of the Organ Procurement and Transplantation Network registry data to administrative billing revealed that with a mean time from donation to end of follow-up of 7.7 years, diagnosed CKD after donation was approximately twice as frequent among donors of African descent than those of Caucasian descent ${ }^{15}$. The contribution of APOL1 polymorphism to this worse clinical outcome remains to be determined.

The mechanisms by which APOL1 polymorphisms are associated with FSGS are not known. The APOL1 risk alleles are still only risk factors for vascular related ESRD and FSGS in African American patients but a direct relationships between the genetic event and 
the pathological process leading to the kidney disease remains to be determined. Possibly, the variable clinical and histological patterns of kidney disease are related to a "two hits" event: firstly a donor related genetic variant and a second hit, which may be viral, metabolic or environmental $^{16}$. It is plausible that nephronic reduction and hyperfiltration related to kidney donation constituted such a second hit in our case.

Our observation is also unusual in that the donor and recipient are monozygotic twin brothers. This is a particularly suitable context for analysing the APOL1-related phenotype/genotype relationship. At the time of donation, the recipient exhibited ESRD with significant proteinuria and hypertension and the donor's kidney function and blood pressure were considered to be normal. The recipient exhibited an early recurrence of FSGS and donor displayed decreased eGFR with mild proteinuria five years post-transplant donation. These different outcomes illustrate the well-known concept of phenotypic discordance between monozygotic twins which might be related to environmental differences but also to epigenetic modifications of histones and DNA ${ }^{17}$ such as DNA methylation profiles ${ }^{18}$.

Finally, we describe the first case of chronic kidney disease in both monozygotic twins carrying APOL1 polymorphism after kidney donation that is known to be a risk factor to graft loss. The mechanisms involved in kidney disease after donation required further experimental and human genetic studies. 


\section{References}

1. Coresh J, Selvin E, Stevens LA, et al. Prevalence of chronic kidney disease in the United States. JAMA. Nov 7 2007;298(17):2038-2047.

2. Tarver-Carr ME, Powe NR, Eberhardt MS, et al. Excess risk of chronic kidney disease among African-American versus white subjects in the United States: a population-based study of potential explanatory factors. J Am Soc Nephrol. Sep 2002;13(9):2363-2370.

3. Genovese G, Friedman DJ, Ross MD, et al. Association of trypanolytic ApoL1 variants with kidney disease in African Americans. Science. Aug 13 2010;329(5993):841-845.

4. Kopp JB, Nelson GW, Sampath K, et al. APOL1 genetic variants in focal segmental glomerulosclerosis and HIV-associated nephropathy. $J$ Am Soc Nephrol. Nov 2011;22(11):2129-2137.

5. Papeta N, Kiryluk K, Patel A, et al. APOL1 variants increase risk for FSGS and HIVAN but not IgA nephropathy. J Am Soc Nephrol. Nov 2011;22(11):1991-1996.

6. Opelz G, Mickey MR, Terasaki PI. Influence of race on kidney transplant survival. Transplant Proc. Mar 1977;9(1):137-142.

7. Pallet N, Thervet E, Alberti C, et al. Kidney transplant in black recipients: are African Europeans different from African Americans? Am J Transplant. Nov 2005;5(11):2682-2687.

8. Young CJ, Gaston RS. Renal transplantation in black Americans. N Engl J Med. Nov 23 2000;343(21):1545-1552.

9. Young CJ, Gaston RS. Understanding the influence of ethnicity on renal allograft survival. Am J Transplant. Nov 2005;5(11):2603-2604.

10. Lee BT, Kumar V, Williams TA, et al. The APOL1 genotype of African American kidney transplant recipients does not impact 5-year allograft survival. Am J Transplant. Jul 2012;12(7):1924-1928.

11. Reeves-Daniel AM, DePalma JA, Bleyer AJ, et al. The APOL1 gene and allograft survival after kidney transplantation. Am J Transplant. May 2011;11(5):1025-1030.

12. Levey AS, Bosch JP, Lewis JB, Greene T, Rogers N, Roth D. A more accurate method to estimate glomerular filtration rate from serum creatinine: a new prediction equation. Modification of Diet in Renal Disease Study Group. Ann Intern Med. Mar 16 1999;130(6):461-470.

13. Lipska BS, Iatropoulos $\mathrm{P}$, Maranta $\mathrm{R}$, et al. Genetic screening in adolescents with steroid-resistant nephrotic syndrome. Kidney Int. Jul 2013;84(1):206-213.

14. Cohen DM, Mittalhenkle A, Scott DL, Young CJ, Norman DJ. African American living-kidney donors should be screened for APOL1 risk alleles. Transplantation. Oct 15 2011;92(7):722-725.

15. Lentine KL, Schnitzler MA, Xiao H, et al. Racial variation in medical outcomes among living kidney donors. N Engl J Med. Aug 19 2010;363(8):724-732.

16. Freedman BI, Langefeld CD, Turner J, et al. Association of APOL1 variants with mild kidney disease in the first-degree relatives of African American patients with non-diabetic end-stage renal disease. Kidney Int. Oct 2012;82(7):805-811.

17. Musselman CA, Lalonde ME, Cote J, Kutateladze TG. Perceiving the epigenetic landscape through histone readers. Nat Struct Mol Biol. Dec 2012;19(12):1218-1227.

18. Kaminsky ZA, Tang T, Wang SC, et al. DNA methylation profiles in monozygotic and dizygotic twins. Nat Genet. Feb 2009;41(2):240-245. 


\section{Figure legends}

Figure 1 Kidney graft biopsy showing typical FSGS lesions, fibrosis and tubular atrophy

Figure 1A: Presence of a small lymphocytic infiltrate in an area of fibrosis. Fibrosis and tubular atrophy. Note the presence of one glomerulus with apparently normal morphology (Periodic acid-Schiff x 20)

Figure 1B: FSGS lesion at the vascular pole of the glomerulus (Periodic acid-Schiff x20)

Figure 2 Evolution of eGFR and Proteinuria before and after transplantation for both donor and recipient.

eGFR is expressed in $\mathrm{ml} / \mathrm{min} / 1.73 \mathrm{~m}^{2}$ according to the 6-variable MDRD formula and proteinuria in $\mathrm{g} / \mathrm{day}$.

B1, B2, B3: Graft biopsy 1, 2 and 3. D1, D2: Dialysis period for recipient. T: Transplantation. Yn: $\mathrm{n}$ years post transplantation

Figure 3 Chromatograms of exon 7 of the APOL1 gene, showing sequences of variants identified as heterozygous composite G1/G2.

The twins express both at-risk alleles: G1 (consisting of variants derived from rs73885319 and rs60910145) that encodes a protein with two nonsynonymous amino acid substitutions, and G2 (rs71785313) that encodes a protein with a deletion of two amino acids from the same $\mathrm{C}$ terminal domain of APOL1.

Arrows indicate the position of the mutations. 